\title{
Responses of healthy young males to fine- particle exposure are modified by exercise habits: a panel study
}

\author{
Xi Chen ${ }^{1,3+}$, Wu Chen ${ }^{1 \dagger}$, Yanwen Wang ${ }^{1}$, Yiqun $\operatorname{Han}^{1}$ and Tong Zhu ${ }^{1,2^{*}}$
}

\begin{abstract}
Background: Aerobic exercise benefits health but increases inhalation of fine particles $\left(\mathrm{PM}_{2.5}\right)$ in ambient air. Acute cardiopulmonary responses to $\mathrm{PM}_{2.5}$ exposure in individuals with different exercise habits, especially in areas with severe air pollution, are not well understood.

Methods: To examine acute cardiopulmonary responses to $\mathrm{PM}_{2.5}$ exposure modified by exercise habits, a panel of 20 healthy non-smoking male subjects, recruited in Beijing, China, completed seven visits. The exercise frequency per week and preferred exercise place were recorded using a baseline questionnaire to describe exercise habits. Fractional exhaled nitric oxide (FeNO), cytokines in exhaled breath condensate, blood pressure, and pulse-wave analysis (PWA) indices were measured during each visit as biomarkers of acute cardiopulmonary responses. The hourly average mass concentration of $\mathrm{PM}_{2.5}$ and black carbon (BC), and the number concentrations of ultrafine particles (UFP) and accumulation mode particles (AMP) were monitored throughout the follow-up period at an outdoor fixed monitoring station beginning 14 days prior to each visit. Linear mixed-effects models were used to evaluate the associations between acute changes in biomarker levels and exposure to $\mathrm{PM}_{2.5}$ and its constituents. The primary aim was to assess the modification of long-term exercise habits on these associations.
\end{abstract}

Results: FeNO concentration, systolic blood pressure, ejection duration, aortic augmentation pressure, and aortic pressure index were positively associated with exposure to $\mathrm{PM}_{2.5}$ and its constituents. However, no associations with cytokine levels or diastolic blood pressure were observed. In a stratified analysis, we found that acute cardiopulmonary responses were modified by exercise habit. Specifically, the interquartile ranges (IQR) of increases in the 6-12-h moving average (MA) $\mathrm{PM}_{2.5}$ and AMP exposure were associated with 19-21\% and 24-26\% increases in FeNO, respectively, in subjects with high exercise frequency; these associations were significantly stronger than those in subjects with low exercise frequency. An IQR increase in 3-11-d MA AMP exposure was associated with a $10-26 \%$ increase in aortic augmentation pressure in subjects with low exercise frequency; this association was significantly stronger than that in subjects with high exercise frequency. An IQR increase in 9-13-d MA UFP exposure was associated with a 13-17\% increase in aortic augmentation pressure in subjects who preferred outdoor exercise; this association was stronger than that in subjects who preferred indoor exercise.

Conclusions: In highly polluted areas, frequent exercise might protect against $\mathrm{PM}_{2.5}$-associated arterial stiffness but exacerbate airway inflammation.

Keywords: $\mathrm{PM}_{2.5}$, Exercise habits, Airway inflammation, Arterial stiffness

\footnotetext{
* Correspondence: tzhu@pku.edu.cn

${ }^{+} \mathrm{Xi}$ Chen and Wu Chen contributed equally to this work.

'State Key Joint Laboratory for Environmental Simulation and Pollution

Control, College of Environmental Sciences and Engineering, Peking

University, Beijing 100871, China

${ }^{2}$ The Beijing Innovation Center for Engineering Science and Advanced

Technology, Peking University, Beijing 100871, China

Full list of author information is available at the end of the article
}

(c) The Author(s). 2018 Open Access This article is distributed under the terms of the Creative Commons Attribution 4.0 International License (http://creativecommons.org/licenses/by/4.0/), which permits unrestricted use, distribution, and reproduction in any medium, provided you give appropriate credit to the original author(s) and the source, provide a link to the Creative Commons license, and indicate if changes were made. The Creative Commons Public Domain Dedication waiver (http://creativecommons.org/publicdomain/zero/1.0/) applies to the data made available in this article, unless otherwise stated. 


\section{Background}

Short- and long-term exposure to fine particles $\left(\mathrm{PM}_{2.5}\right.$, particulate matter with an aerodynamic diameter $\leq 2.5 \mu \mathrm{m}$ ) in ambient air is strongly linked to adverse effects on human health, ranging from subclinical changes in cardiopulmonary biomarkers to premature mortality and morbidity [1-3]. Pulmonary and systemic inflammation, oxidative stress, increased blood coagulation, autonomic and vascular imbalance, and endothelial dysfunction have been reported as mechanisms of the cardiopulmonary effects of $\mathrm{PM}_{2.5}$ [4-6]. Black carbon (BC), ultrafine particles (UFP), and accumulation mode particles (AMP) may contribute to the cardiopulmonary effects of $\mathrm{PM}_{2.5}$ exposure [4, 7-11].

Long-term moderate exercise improves endothelial function, adaptation of the cardio-pulmonary system, and resistance to infection, as well as contributing to the prevention and treatment of several chronic diseases, including hypertension and diabetes [12-20]. The benefits of physical exercise can be attributed to the release of vasoconstrictor substances, increased cardiac rhythm and force, and increased nitric oxide bioavailability [12, 21-25].

Exercise in highly polluted environments reportedly increased the inhalation of air pollutants, including $\mathrm{PM}_{2.5}$, due to increased respiratory rate, inappropriate mouth breathing, and reduction of nasal resistance [4, 26-29]. However, the results of studies on the combined health outcomes of long-term exercise and air pollution are inconsistent $[16,17,25,30]$. Several studies have reported that the beneficial effects of long-term moderate exercise outweigh the adverse effects of air pollutants [13, 15, 19, 31, 32]. In contrast, long-term exercise might also aggravate air pollutant-associated respiratory impairment, including decreased resistance to upper respiratory tract infections, pulmonary dysfunction, and increased prevalence of airway hyper-responsiveness $[19,33,34]$.

The inconsistent results of studies on the influence of long-term physical exercise on particle-related cardiopulmonary responses may be due to various confounders, particularly the heterogeneity of the study subjects and their exercise habits [19, 31-33]. Also, most studies were conducted in areas of relatively low pollution, such as North American or European countries $[13,26,31,33,35-37]$. The lack of evidence in high-pollution areas has limited discussion on the effects of physical exercise on the cardiopulmonary response to $\mathrm{PM}_{2.5}$ exposure [38]. In this study, we assessed the associations between $\mathrm{PM}_{2.5}$ exposure and acute cardiopulmonary responses in a panel of healthy young male adults and examined the effects on this associations of long-term exercise habits to determine whether individuals benefit from or are impaired by long-term regular exercise in Beijing, an area with high levels of air pollutants.

\section{Methods}

\section{Study design and subjects}

In the winter of 2014, during the heating season, a period of severe pollution, a panel study was conducted to evaluate acute cardiopulmonary responses to $\mathrm{PM}_{2.5}$ exposure in healthy young adults in Beijing, China. Twenty non-smoking male subjects aged 18-26 years were recruited and required to complete a survey of medical history and a baseline questionnaire. No subject reported a history of severe cardiopulmonary illness or regular medication use. The study was approved by the Ethics Committee of Peking University Health Sciences Centre (IRB00001052-14076), and written consent was obtained from all of the subjects.

All subjects completed a total of seven visits spaced 5-7 days apart. During each visit, all subjects underwent a health measurement on the same day. Subjects were asked to refrain from alcohol, caffeine, and exercise for $24 \mathrm{~h}$ before measurement. All subjects rested for $20 \mathrm{~min}$ and completed a follow-up questionnaire comprising questions on the following: sleep, exercise, and dietary habits, second-hand smoke exposure $(>0.5 \mathrm{~h})$, and clinical respiratory and cardiovascular symptoms within 24 $\mathrm{h}$ prior to the visit. Weight and body fat ratio (BFR) were measured for each subject using a body-fat scale (HBF-358-BW; Omron Healthcare, Inc., Dalian, Liaoning, China), and height was measured using a meter stick. Body mass index (BMI) was calculated as the weight divided by the square of the height. Bio-samples were collected from the subjects at a fixed time of day during all seven visits to control for diurnal variation in biological indicators.

\section{Exercise habits}

Information on subjects' exercise habits was collected in the baseline questionnaire. Subjects were asked to recall their exercise habits in the past year, including exercise frequency and place. Exercise frequency referred to the number of exercise sessions per week. Exercise frequencies of more (less) than once per week were regarded as high (low) exercise frequency. Exercise place referred to the location where subjects habitually undertook physical exercise, including indoor and outdoor locations. Subjects were asked to maintain their exercise habit for 14 days prior to visits and during the entire follow-up period and to report atypical exercise conditions in the follow-up questionnaires.

\section{Exposure measurement}

The concentrations of $\mathrm{PM}_{2.5}$ and its constituents were measured continuously using a fixed-site monitor located on the rooftop of a building ( $\sim 18 \mathrm{~m}$ in height), which was within $2 \mathrm{~km}$ of the subjects' major residences. The monitoring commenced 14 days prior to the visits 
and continued throughout the follow-up period. The mass concentration of $\mathrm{PM}_{2.5}$ was monitored with 1 min resolution using a tapered element oscillating microbalance sampler (TEOM) (Model 1405; Thermal Electron Corp., Waltham, MA, USA). Particle number concentration in the size range $5.6-560 \mathrm{~nm}$ was monitored at 1 -min resolution using a fast mobility particle sizer (FMPS) (Model 3091; TSI, Inc., Shoreview, MN, USA) and divided into UFP $(5.6-100 \mathrm{~nm})$ and AMP $(100-560 \mathrm{~nm})$. The mass concentration of $\mathrm{BC}$ was monitored at 5 min resolution using a multi-angle absorption photometer (MAAP) (Model 5012; Thermal Electron Corp., Waltham, MA, USA). Temperature and relative humidity were monitored at hourly resolution using a weather station attached to a four-channel aerosol sampler (TH - 16A; Tianhong, Inc., Wuhan, China). All concentrations were averaged into hourly data for further analysis.

All instruments were maintained and calibrated weekly. The cyclone dust collector and particles cutting head of the FMPS, MAAP, and TEOM, as well as the electric bucket of the FMPS were cleaned softly using dust-free gauze. The zero points of the MAAP and TEOM were calibrated using the self-calibration mode. After connecting the FMPS to the high-efficiency particulate air filter for $>10 \mathrm{~min}$, each channel was calibrated for the zero point. Maintenance took $2 \mathrm{~h}$ daily.

\section{Respiratory and cardiovascular biomarkers}

Fractional exhaled nitric oxide (FeNO) samples were collected by an off-line sampling method as described previously [10]. Subjects were asked to inhale through activated carbon to remove ambient $\mathrm{NO}$, and exhale into individual aluminum bags at a flow rate of $150 \mathrm{~L} / \mathrm{h}$ and positive pressure of $13 \mathrm{~cm} \mathrm{H}_{2} \mathrm{O}$ as $\mathrm{FeNO}$ samples. The samples were analyzed for $\mathrm{NO}$ concentration using an $\mathrm{NO} / \mathrm{NO}_{2} / \mathrm{NO}_{\mathrm{x}}$ analyzer (Model $42 \mathrm{i}$; Thermo Scientific Corp., Waltham, MA, USA). Exhaled breath condensates $(E B C)$ were collected using a Jaeger EcoScreen collector (Erich Jaeger, Friedberg, Germany). The procedure was described previously [39]. Subjects were asked to inhale and exhale smoothly through the machine using only their mouths. After collection, EBC samples were de-aerated with inert argon gas, aliquoted in labeled cryotubes, and immediately stored at $-80^{\circ} \mathrm{C}$. The levels of interleukin- $2 / 1 \beta / 6(\mathrm{IL}-2 / 1 \beta / 6)$, tumor necrosis factor- $\alpha$, and interferon- $\gamma$ in EBC were measured using cytometric bead array and flow cytometry techniques (BD Biosciences, San Diego, CA, USA).

Blood pressure measurements and pulse-wave analysis (PWA) were performed in a quiet, private environment with subjects in the prone position to ensure that the elbow was at the level of the heart. First, medical mercury sphygmomanometers (Jiangsu Yuyue Medical Equipment \& Supply Corp., Jiangsu, China) were used to measure peripheral systolic and diastolic blood pressure (SBP and DBP) three times at 2-min intervals, and the averages were used for subsequent analyses. Peripheral pulse pressure was calculated as the difference between SBP and DBP (pulse pressure $=$ SBP - DBP). Next, applanation tonometry using a high-fidelity micromanometer (SphygmoCor; AtCor Medical, Sydney, Australia) was used to record radial arterial pressure waveforms at the wrist of the dominant arm non-invasively. The homogeneity of the observed waveforms was assessed using the built-in quality score. The peripheral waveforms were transformed into corresponding central aortic waveforms via a mathematical function [40]. PWA measurements, including aortic augmentation pressure, augmentation index, and heart ejection duration, were determined using the 15-s sequential aortic pressure waveforms and were considered indicators of endothelial function and blood supply capacity [41, 42]. Specifically, the aortic augmentation pressure was defined as the average difference between the second and first systolic peaks of the 15-s sequential aortic pressure waveforms, and the aortic pressure index was defined as the ratio of the aortic augmentation pressure to the peripheral pulse pressure [41, 43].

\section{Statistical analysis}

Linear mixed-effects (LMEs) models were used to estimate the associations between acute cardiopulmonary responses and exposure to $\mathrm{PM}_{2.5}$ and its constituents. The fixed and random effects of the LME models were estimated by the restricted maximum-likelihood method. Random subject-specific intercepts were included in the models to control for within-subject variation among the seven repeated measurements, but the random slopes were not considered. The dependent variables were the levels of the biomarkers, which were logarithmically transformed because of their non-normal distribution. The independent variables were the moving average (MA) concentrations of $\mathrm{PM}_{2.5}$, including the mass concentrations of $\mathrm{PM}_{2.5}$ and $\mathrm{BC}$ and the number concentrations of UFP and AMP, prior to each visit. All of the LME models were adjusted for ambient temperature and relative humidity to account for their potential impact on the levels of the biomarkers.

In stratified analyses, the single-pollutant LME models included BMI or BFR or exercise frequency or exercise place as a first-order interaction term to estimate the exposure-response associations modified by exercise habits, which was the primary aim of this study. For instance, in the formula used to assess the effects of exercise frequency on the associations: biomarker $=\beta_{1}$ exposure $+\beta_{2}{ }^{*}$ exercise frequency $+\beta_{3}{ }^{*}$ exposure $\times$ exercise frequency, the regression coefficients in the additive LME model for subjects with low and high exercise frequencies were $\beta_{1}$ and $\left(\beta_{1}+\beta_{3}\right)$, respectively. In a sensitivity analysis, a single-pollutant LME model was used to evaluate whether the exposure-response associations changed after further adjustment for age, 
breakfast, sleep quality, second-hand smoke exposure, and the daily sleeping, working, and outdoor times. Two-pollutant LME models were used to examine the consistency of the estimated results of the single-pollutant LME models by further adjustment for all combinations of pollutant metrics.

The final results ( $\beta$-coefficient) of the LME models are reported as the estimated percentage changes in the dependent variables for each interquartile range (IQR) increase in pollutant concentrations. Results were calculated as $\beta=\left[\left(\exp ^{\wedge}\left(\beta^{\prime} \times I Q R\right)\right)-1\right] \times 100 \%$, where $\beta^{\prime}$ is the estimated effect of the corresponding model. The $95 \%$ confidence intervals (CIs) were transformed using the same formula as for $\beta$. Statistical significance was considered present at $p<0.05$. All data analyses were conducted using R statistical software (ver. 3.1; R Development Core Team, Vienna, Austria).

\section{Results}

\section{General data: Descriptive statistics}

In total, 20 subjects completed seven visits, but 13 of the 140 records labelled with acute respiratory symptoms or medication use were intentionally deleted. Before visits. The general characteristics of the subjects are shown in Table 1 . The ranges of daily sleeping, working, and outdoor times of the subjects were small, which suggested that these healthy young male non-smokers had similar living conditions. The proportions of the visits at which the subjects reported having had breakfast, poor sleep quality, and second-hand smoke exposure before biomarker collection were 24,39 , and $7 \%$, respectively. Among the subjects, 50 and $45 \%$ exercised more than once per week and usually exercised outdoors, respectively. Six subjects exercised more than once per week and also preferred outdoor exercise. The median BMI and BFR values were $23.0 \mathrm{~kg} / \mathrm{m}^{2}$ and $18.0 \%$, respectively. The averaged levels of FeNO, SBP, and DBP, and the ejection duration, aortic augmentation pressure, and aortic pressure indices were $17.1 \pm 10.4 \mathrm{ppb}, \quad 123 \pm 10 \mathrm{mmHg}, 72 \pm 7 \mathrm{mmHg}$, $37 \pm 4 \%,-1 \pm 2 \mathrm{mmHg}$, and $-2 \pm 8 \%$, respectively. The averaged IL-2 level was $8.0 \pm 0.8 \mathrm{pg} / \mathrm{mL}$, and the levels of other cytokines in EBC were below the limits of detection.

The distribution of air-pollutant exposure during the follow-up period is shown in Table 2. Missing data included $\mathrm{PM}_{2.5}$ measurement at $83 \mathrm{~h}, \mathrm{BC}$ measurement at $236 \mathrm{~h}$, and UFPs and AMP measurements at $191 \mathrm{~h}$ due to temporary power outages or extreme weather. The mass concentrations of $\mathrm{PM}_{2.5}$ and $\mathrm{BC}$ were $65.2 \pm 69.6$ and $5.3 \pm 4.2 \mu \mathrm{g} / \mathrm{m}^{3}$, respectively. The number concentrations of UFP and AMP were $16.2 \pm 7.3$ and $4.6 \pm 3.810^{3} / \mathrm{cm}^{3}$, respectively. Compared with most former studies of the combined effects of ambient air pollution exposure and physical exercise [26, 31, 35-37], the levels of $\mathrm{PM}_{2.5}$ and its constituents were higher,
Table 1 Characteristics of the subjects and baseline biomarkers measurements

\begin{tabular}{llll}
\hline Characteristics/biomarkers & $n$ & Mean/\% (SD) & Median (Range) \\
\hline Age (year) & 20 & $23(2)$ & $23(18-26)$ \\
Daily Sleeping Time (hr) & 20 & $7(1)$ & $7(3-10)$ \\
Daily Working Time (hr) & 20 & $5(2)$ & $5(3-8)$ \\
Daily Outdoor Time (hr) & 20 & $3(2)$ & $3(1-6)$ \\
Breakfast before Visit & & & \\
$\quad$ Yes & 31 & $24 \%$ & \\
No & 96 & $76 \%$ &
\end{tabular}

Poor Sleep Quality before Visit

$\begin{array}{lll}\text { Yes } & 49 & 39 \% \\ \text { No } & 78 & 61 \%\end{array}$

Second-Hand Smoke Exposure ${ }^{a}$ (Past 24-h)

$\begin{array}{lll}\text { Yes } & 9 & 7 \% \\ \text { No } & 118 & 93 \%\end{array}$

Weekly Aerobic Exercise $\geq 2 /$ week (Past 3-years)

Yes $\quad 10 \quad 50 \%$

No $\quad 10 \quad 50 \%$

Outdoor Exercise

Yes $\quad 9 \quad 45 \%$

No $\quad 11 \quad 55 \%$

Body Mass Index $\left(\mathrm{kg} / \mathrm{m}^{2}\right) \quad 20 \quad 22.4(2.8) \quad 23.0(15.6-27.8)$

Body Fat Rate (\%) $\quad 20 \quad 18.5(4.1) \quad 18.0(8.6-26.5)$

$\begin{array}{llll}\text { FeNO }(\mathrm{ppb}) & 127 & 17.1(10.4) & 14.0(2.3-48.3)\end{array}$

$\begin{array}{llll}\mathrm{IL}-2(\mathrm{pg} / \mathrm{mL}) & 115 & 8.0(0.8) & 8.1(7.2-10.3)\end{array}$

$\mathrm{SBP}(\mathrm{mmHg}) \quad 127 \quad 123(10) \quad 122(104-132)$

$\mathrm{DBP}(\mathrm{mmHg}) \quad 127 \quad 72(7) \quad 72(58-80)$

$\begin{array}{llll}\text { Ejection duration (\%) } & 127 & 37(4) & 37(27-47)\end{array}$

$\begin{array}{llll}\text { Aortic augmentation } & 127 & -1(2) & 0(-7-4)\end{array}$ pressure $(\mathrm{mmHg})$

Aortic pressure index (\%) $127 \quad-2(8) \quad-1(-19-13)$

Abbreviations: FeNO, fractional exhaled nitric oxide; IL-2, interleukin-2; SBP and DBP: peripheral systolic and diastolic blood pressure

${ }^{a}$ it only included exposures which lasted more than $0.5 \mathrm{hr}$

Table 2 Distributions of air pollutants and meteorological parameters (hourly average) during the follow-up period

\begin{tabular}{llll}
\hline Variables & $n$ & Mean (SD) & IQR \\
\hline PM $2.5\left(\mu \mathrm{g} / \mathrm{m}^{3}\right)$ & 1261 & $65.2(69.6)$ & $5.8-106.2$ \\
$\mathrm{BC}\left(\mu \mathrm{g} / \mathrm{m}^{3}\right)$ & 1108 & $5.3(4.2)$ & $1.0-8.9$ \\
$\mathrm{UFP}\left(10^{3} / \mathrm{cm}^{3}\right)$ & 1153 & $16.2(7.3)$ & $11.4-20.8$ \\
AMP $\left(10^{3} / \mathrm{cm}^{3}\right)$ & 1153 & $4.6(3.8)$ & $0.7-7.6$ \\
Temperature $\left({ }^{\circ} \mathrm{C}\right)$ & 1344 & $1.3(3.3)$ & $-1.2-3.5$ \\
Relative Humidity $(\%)$ & 1344 & $24.8(12.7)$ & $1.5-31.5$
\end{tabular}

Abbreviation: $\mathrm{PM}_{2.5}$, fine particles; $\mathrm{BC}$, black carbon; UFP, ultrafine particles; AMP, particles in accumulation mode 
and the ranges were wider in our study. For instance, in a study conducted in Europe, the annual average concentration of $\mathrm{PM}_{2.5}$ was $14.8 \pm 1.8 \mu \mathrm{g} / \mathrm{m}^{3}$ [31]. In another European study, the median (IQR) of BC exposure during a 24-h period was $1.4(1.1-1.8) \mu \mathrm{g} / \mathrm{m}^{3}$ [35]. Weichenthal et al. performed a cross-over study in Canada, which showed that the weekly average levels of $\mathrm{PM}_{2.5}, \mathrm{BC}$, and UFP around a traffic route were $14.2 \pm 1.3 \mu \mathrm{g} / \mathrm{m}^{3}, 1.7 \pm 1.4 \mu \mathrm{g} / \mathrm{m}^{3}$, and $16.8 \pm 10.310^{3} / \mathrm{cm}^{3}$, respectively [36].

As shown in Additional file 1: Table S1 and S2, the concentrations of $\mathrm{PM}_{2.5}, \mathrm{BC}$, and AMP were highly correlated (Pearson correlation coefficient $\geq 0.8, p \leq 0.001$ ). The Pearson correlation coefficients between the number concentration of UFP and other pollutants were relatively low, suggesting different sources of UFP. With the exception of the correlation between aortic augmentation pressure and the aortic pressure index (Pearson correlation coefficient $=0.975)$, the biomarker levels were not highly correlated.

\section{Results of LME models for all subjects}

The results of single-pollutant LME models for all subjects are shown in Additional file 1: Figure S1-S7. Increased FeNO concentrations were significantly and consecutively associated with 2-6-h MA exposure to $\mathrm{PM}_{2.5}$ and its constituents $(\beta=16-40 \%)$. Increased SBP was associated with 5- and 7-d MA exposure to AMP $(\beta=1-2 \%)$. Increased ejection duration was significantly associated with 2-h and 9-d MA exposure to $\mathrm{PM}_{2.5}$ and its constituents $(\beta=1-2 \%)$. Increased aortic augmentation pressure was significantly and consecutively associated with 7-9-d MA exposure to $\mathrm{PM}_{2.5}$ and $\mathrm{BC}(\beta=5-10 \%)$, and 7-13-d MA exposure to UFP and AMP $(\beta=5-13 \%)$.
An increased aortic pressure index was significantly and consecutively associated with 5-9-d MA exposure to $\mathrm{PM}_{2.5}$ and $\mathrm{BC}(\beta=5-26 \%)$ and 9-13-d MA exposure to UFP and AMP ( $\beta=7-13 \%)$. The levels of IL-2 and DBP were not associated with $\mathrm{PM}_{2.5}$ exposure.

The results of the two-pollutant LME models are shown in Additional file 1: Figure S8. The associations between the levels of the biomarkers and UFP exposure remained robust and significant after adjustment for the levels of other pollutants. The associations of the levels of $\mathrm{FeNO}$ with ejection duration and $\mathrm{BC}$ exposure were also relatively robust. In addition, according to the sensitivity analysis (Additional file 1: Table S3), taking the effect of UFP exposure as an example, the results of LME models were not affected by age, breakfast, sleep quality, second-hand smoke exposure, or the daily sleeping, working, and outdoor times.

\section{Stratified analyses of LME models}

The association between FeNO elevation and particle exposure was analyzed stratified by habitual exercise frequency (Fig. 1). IQR increases in 6-h MA exposure to $\mathrm{PM}_{2.5}$ and AMP were associated with $19 \%(\mathrm{CI}=9-29 \%)$ and $26 \%(\mathrm{CI}=11-41 \%)$ increases in the FeNO concentration, respectively, in subjects with high exercise frequency; these increases were significantly greater than those in subjects with low exercise frequency. IQR increases in 12-h MA exposure to $\mathrm{PM}_{2.5}$ and AMP were associated with $21 \%$ $(\mathrm{CI}=12-30 \%)$ and $24 \%(\mathrm{CI}=10-37 \%)$ increases in FeNO concentration, respectively, in subjects with high exercise frequency; these increases were significantly greater than those in subjects with low exercise frequency. The changes in FeNO concentration associated with exposure to $\mathrm{BC}$ and

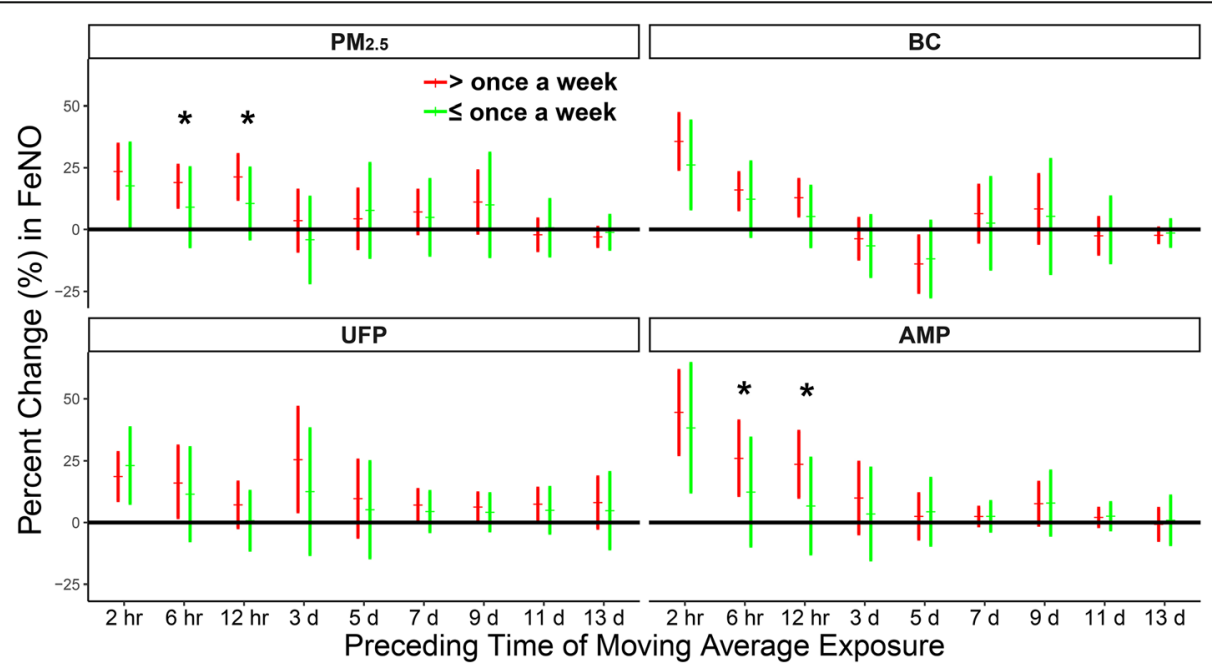

Fig. 1 Changes in FeNO associated with IQR increases in concentrations of $\mathrm{PM}_{2.5}$ and its constituents stratified by exercise frequency. The models are adjusted for ambient temperature and relative humidity. Red and green error bars show estimated changes in subjects who exercise more and less than once per week, respectively. ${ }^{\star}$ Significant $(p<0.05)$ differences between estimates 
UFP did not differ between subjects with high and those with low exercise frequencies.

The association between aortic augmentation pressure elevation and particle exposure was analyzed stratified by habitual exercise frequency (Fig. 2). IQR increases in 3-, 5-, 7-, and 11-d MA AMP exposure were associated with $26 \%(\mathrm{CI}=9-44 \%), 20 \%(\mathrm{CI}=4-35 \%), 10 \%(\mathrm{CI}=3-16 \%)$, and $11 \%(\mathrm{CI}=5-15 \%)$, respectively, increases in aortic augmentation pressure in subjects with low exercise frequency; these increases were significantly greater than those in subjects with high exercise frequency. The aortic augmentation pressure elevations associated with 5-d BC, 5-11-d UFP, and 9- and 13-d AMP MA exposure were marginally significantly higher in subjects with low exercise frequency.

The association between aortic augmentation pressure elevation and particle exposure was analyzed stratified by exercise place (Fig. 3). IQR increases in the 9-, 11-, and 13-d MA UFP exposure were associated with $17 \%$ $(\mathrm{CI}=9-26 \%), 17 \%(\mathrm{CI}=9-25 \%)$, and $13 \%(\mathrm{CI}=6-30 \%)$, respectively, increases in aortic augmentation pressure in subjects who preferred outdoor exercise; these increases were significantly greater than those in subjects who preferred indoor exercise. The changes in aortic augmentation pressure associated with $\mathrm{PM}_{2.5}, \mathrm{BC}$, and AMP exposure were not analyzed stratified by exercise place. In addition, no stratification in the changes in IL-2 level, SBP, DBP, ejection duration, and aortic pressure index associated with particle exposure was observed in LME The associations between the levels of biomarkers and particle exposure were not modified by BMI or BFR (Additional file 1: Figure S9-S32).

\section{Levels of FeNO and aortic augmentation pressure}

In several time windows, e.g., $6 \mathrm{~h}$ and $11 \mathrm{~d}$, LME models showed that the associations of FeNO level or aortic augmentation pressure with particle exposure differed according to exercise frequency and place. Comparisons of the responses of different subgroups to high and low particle concentrations helped to explain the results of the LME models.

The variation in FeNO concentration across seven visits and the corresponding 6-h MA $\mathrm{PM}_{2.5}$ concentration prior to each visit are shown in Fig. 4. The concentrations of FeNO in subjects with low and high exercise frequencies were similar following exposure to a low level of $\mathrm{PM}_{2.5}$ but differed following exposure to a high level of $\mathrm{PM}_{2.5}$. For instance, at visit $2\left(\mathrm{PM}_{2.5}, 45.0 \pm 3.9 \mu \mathrm{g} / \mathrm{m}^{3}\right)$, the concentration of FeNO was $7.4 \pm 2.6$ and $7.7 \pm 0.7 \mathrm{ppb}$ in subjects with high and low exercise frequencies, respectively; at visit $4\left(\mathrm{PM}_{2.5}, 112.0 \pm 7.2 \mu \mathrm{g} / \mathrm{m}^{3}\right)$, the concentration of FeNO in subjects with high exercise frequency was $27.9 \pm 10.7 \mathrm{ppb}$, significantly higher than that in subjects with low exercise frequency $(17.0 \pm 7.9 \mathrm{ppb})$.

The variation in aortic augmentation pressure across seven visits and the corresponding 11-d MA AMP and UFP concentrations prior to each visit are shown in Figs. 5 and 6. The differences in aortic augmentation pressure between subjects with high and those with low exercise frequencies were greater following high-level compared to low-level $\mathrm{PM}_{2.5}$ exposure. For instance, at visit 5 (AMP, $0.9 \pm 0.110^{3} / \mathrm{cm}^{3}$ ), the aortic augmentation pressure was $-2 \pm 3$ and $-2 \pm 2 \mathrm{mmHg}$ in subjects with high and low exercise frequency, respectively; at visit 3 (AMP, $4.5 \pm 0.410^{3} / \mathrm{cm}^{3}$ ), the aortic augmentation pressure in subjects with high exercise frequency was $-2 \pm 3 \mathrm{mmHg}$,

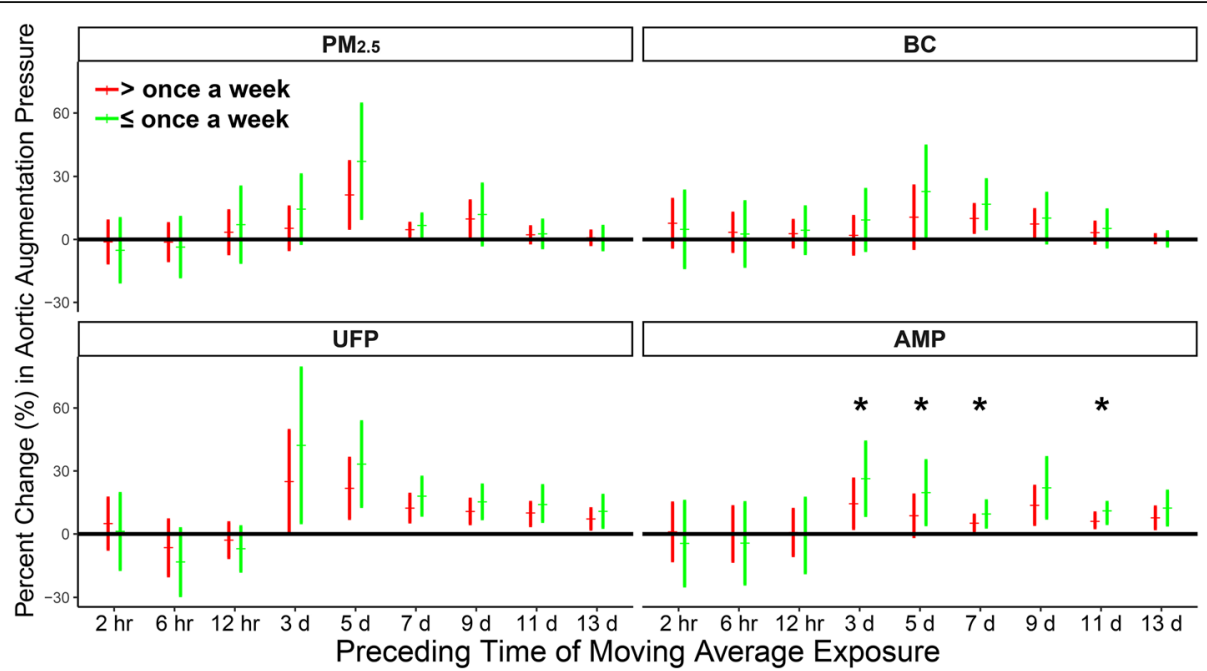

Fig. 2 Changes in aortic augmentation pressure associated with IQR increases in concentrations of PM 2.5 and its constituents stratified by exercise frequency. The models are adjusted for ambient temperature and relative humidity. Red and green error bars indicate estimated changes in subjects who exercise more and less than once per week, respectively. ${ }^{\star}$ Significant $(p<0.05)$ differences between estimates 


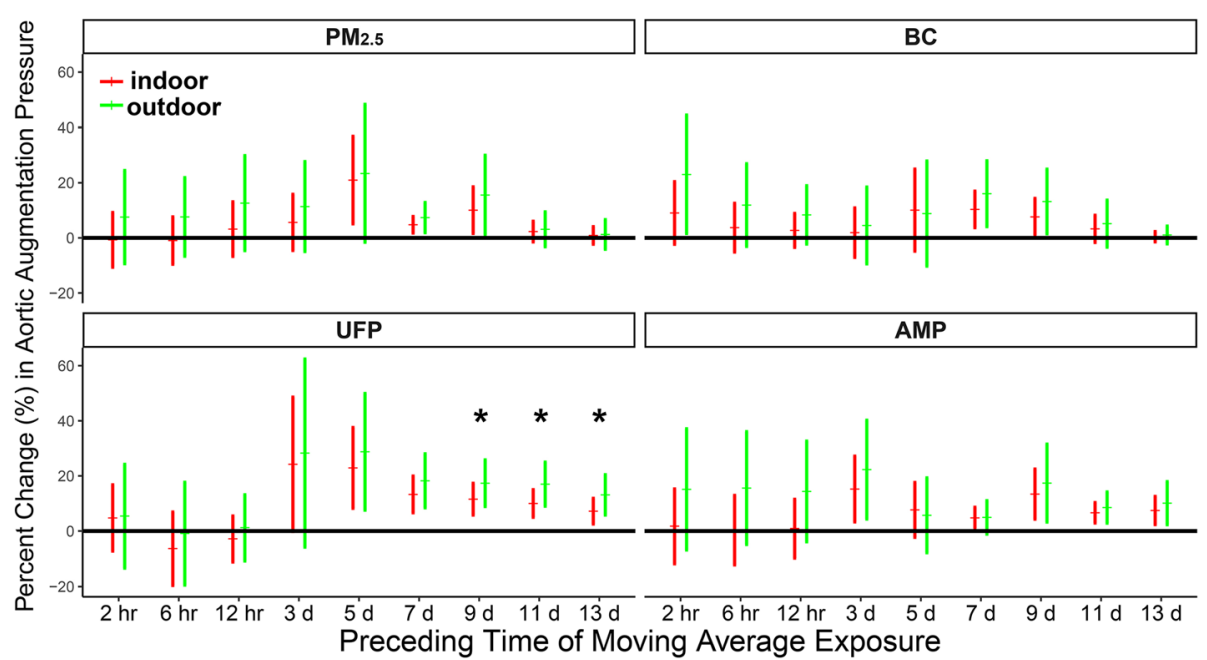

Fig. 3 Changes in aortic augmentation pressure associated with IQR increases in concentrations of $P_{2.5}$ and its constituents stratified by exercise place. The models are adjusted for ambient temperature and relative humidity. Red and green error bars show estimated changes in subjects who prefer indoor and outdoor exercise, respectively. ${ }^{\star}$ Significant $(p<0.05)$ differences between estimates

significantly lower than that in subjects with low exercise frequency $(0 \pm 2 \mathrm{mmHg})$. The difference in aortic augmentation pressure between subjects who preferred indoor and outdoor exercise was smaller at visits following high-level than at those following low-level UFP exposure (Fig. 5). For instance, at visit 5 (UFP, $10.0 \pm 0.310^{3} / \mathrm{cm}^{3}$ ), the aortic augmentation pressure in subjects who preferred indoor exercise was $-1 \pm 2 \mathrm{mmHg}$, higher than that in subjects who preferred outdoor exercise $(-3 \pm 2 \mathrm{mmHg})$. At visit 6
(UFP, $17.2 \pm 0.110^{3} / \mathrm{cm}^{3}$ ), the aortic augmentation pressure was $0 \pm 2$ and $0 \pm 2 \mathrm{mmHg}$ in subjects who preferred indoor and outdoor exercise, respectively.

\section{Discussion}

The results of this study were consistent with prior reports of positive associations between $\mathrm{PM}_{2.5}$ exposure and increased respiratory inflammation and arterial stiffness in healthy young adults (Additional file 1: Table S4) [44-52].

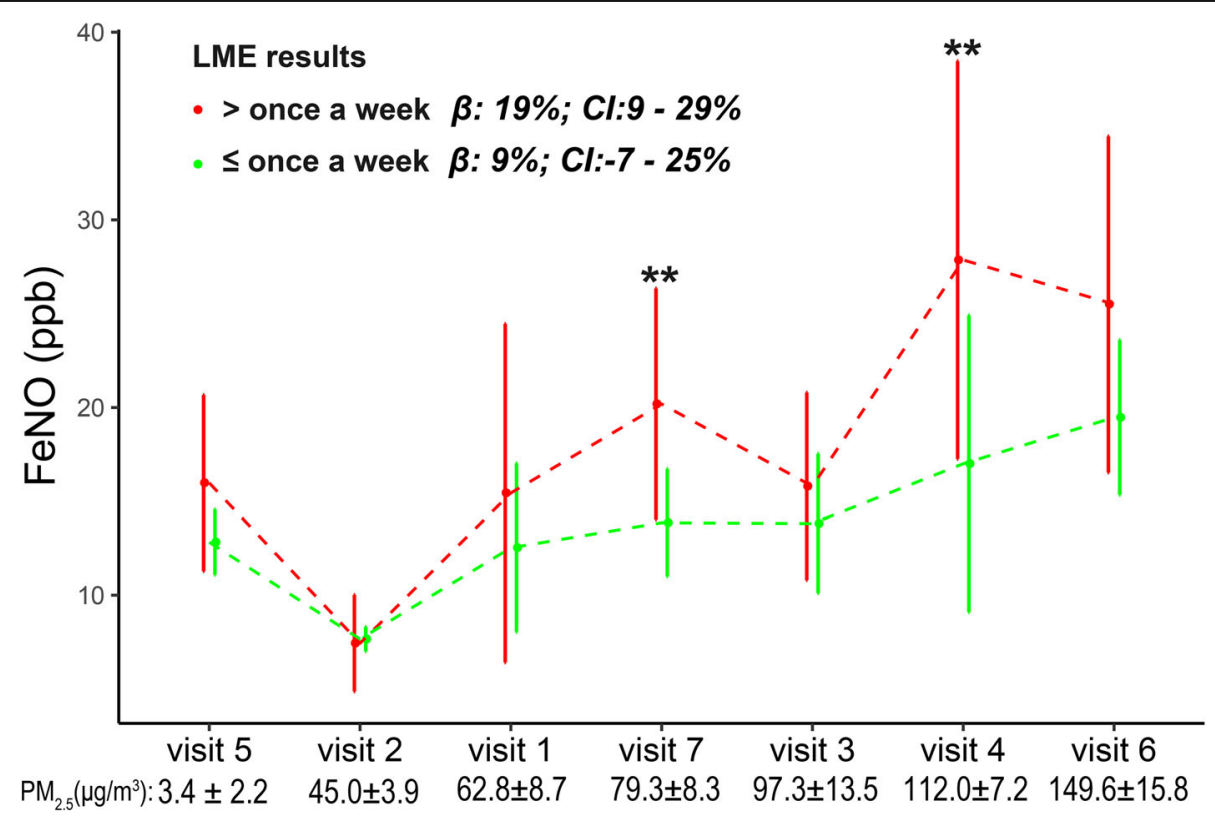

Fig. 4 Level of FeNO (mean \pm SD) at seven visits according to exercise frequency. The visits are ordered by the prior 6-h MA PM 2.5 exposure (bottom). $\beta$, estimated change in the FeNO level per IQR increase in $\mathrm{PM}_{2.5}$ exposure in the LME models. The LME models are adjusted for ambient temperature and relative humidity. ${ }^{* *}$ Significant difference in FeNO between subjects who exercise more and less than once per week by unpaired $t$-test 


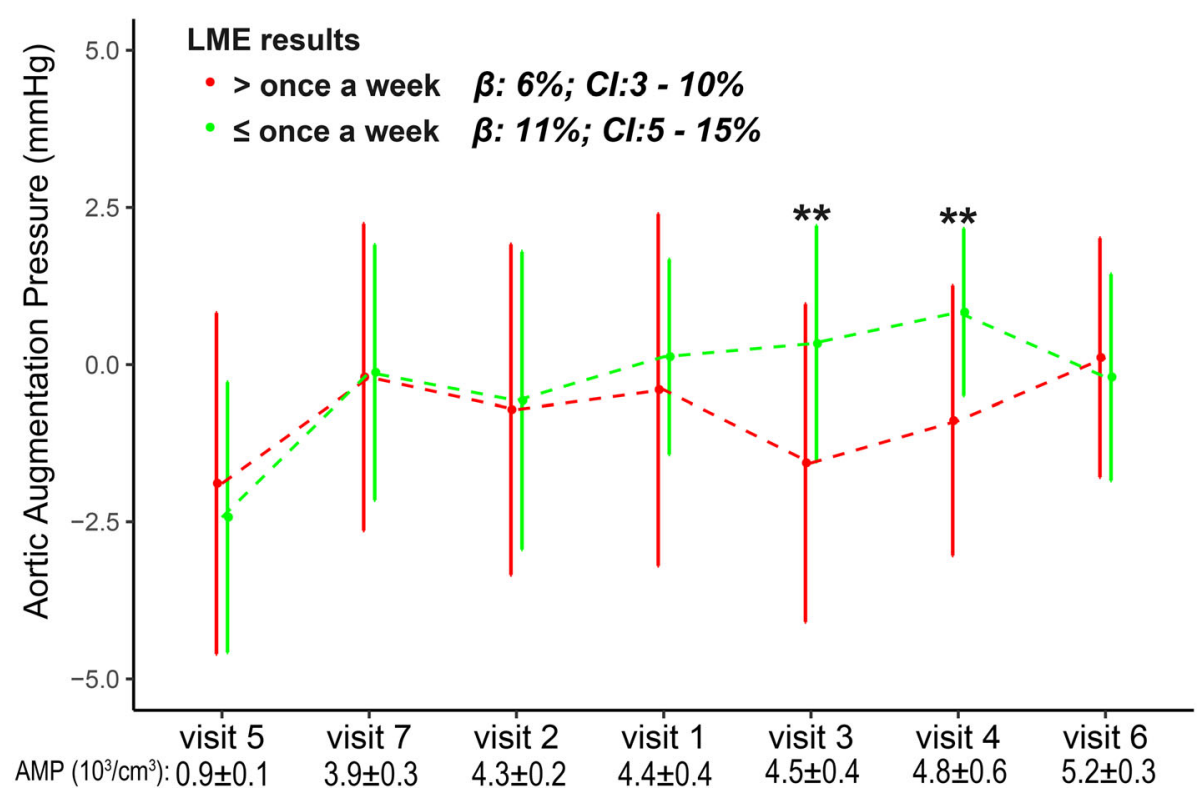

Fig. 5 Aortic augmentation pressure (mean $\pm S D$ ) at seven visits according to exercise frequency. The visits are ordered by prior 11-d MA AMP exposure (bottom). B, estimated change in aortic augmentation pressure per IQR increase in AMP exposure in the LME models. All LME models were adjusted for ambient temperature and relative humidity. ${ }^{*}$ Significant difference in aortic augmentation pressure between subjects who exercise more and less than once per week by unpaired t-test

Changes in FeNO concentration, aortic augmentation pressure, and aortic pressure index associated with $\mathrm{PM}_{2.5}$ exposure in this study were modified by exercise habits, suggesting a combined effect of long-term habitual exercise and $\mathrm{PM}_{2.5}$ exposure. However, some studies observed no particle-mediated acute increases in FeNO, ejection duration, aortic augmentation pressure, or aortic pressure index in healthy young adults. The inconsistency between those results and ours might reflect differences in the subjects recruited and the time windows chosen, as well

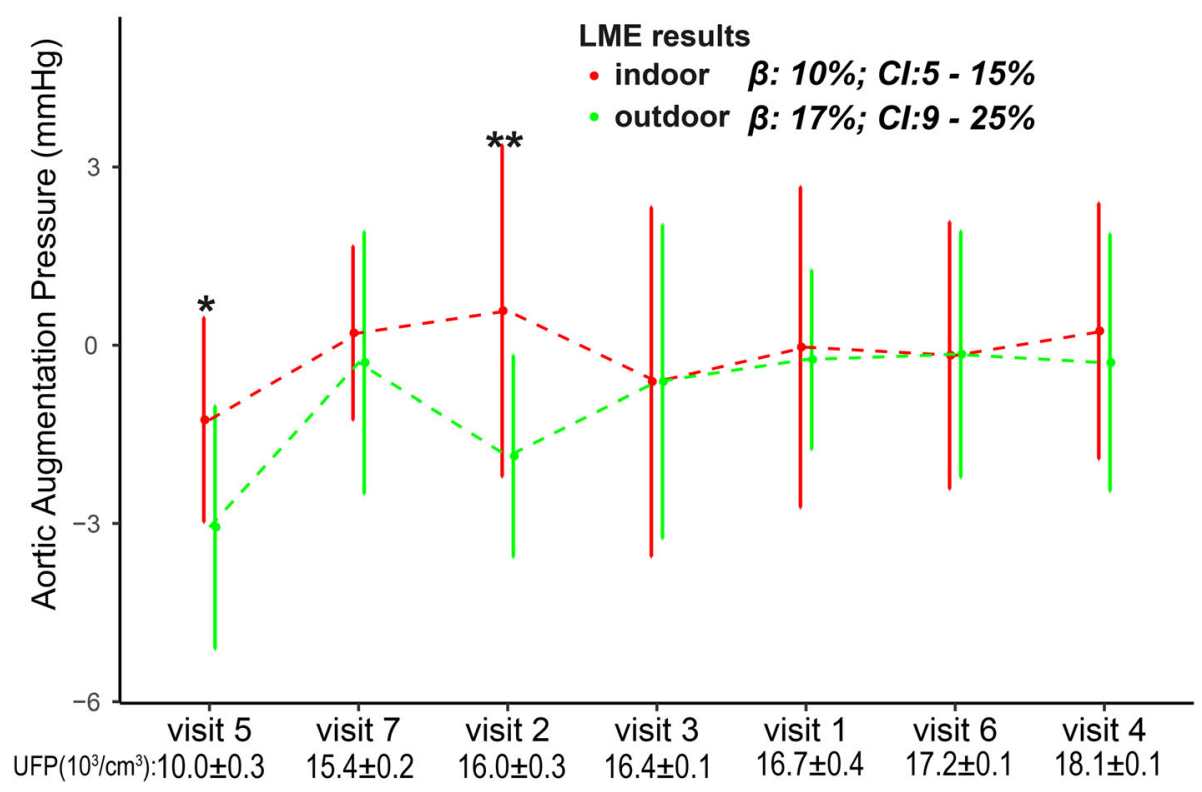

Fig. 6 Aortic augmentation pressure (mean \pm SD) at seven visits in subjects who preferred indoor (red) and outdoor (green) exercise. The visits are ordered by the 11-d MA UFP exposure before visits, which are listed at the bottom. B, estimated change in aortic augmentation pressure per IQR increase in UFP exposure in the LME models. LME models were adjusted for ambient temperature and relative humidity. ${ }^{*}$ Significant difference in aortic augmentation pressure between indoor and outdoor exercise by unpaired t-test 
as the relatively lower levels of particle exposure in previous studies [52-60].

Consistent with previous studies $[10,11,39]$, the concentration of FeNO, a biomarker of eosinophilic airway inflammation, was positively associated with air-pollution exposure, and $\mathrm{PM}_{2.5}$-mediated changes in the FeNO concentration were greater in subjects with high exercise frequency. These results may explain why individuals who engage in high-strength exercise may be at higher risk of particle-mediated respiratory symptoms. Consistent with our results, in a study on chronic respiratory responses to $\mathrm{PM}_{2.5}$ inhalation during exercise [61], competitive athletes were found to be susceptible to pulmonary inflammation and had decreased lung function and an increased risk of asthma. The control group, comprising individuals who engaged in exercise less frequently, was not susceptible to these effects of $\mathrm{PM}_{2.5}$ inhalation. Bougault et al. reported that the number of training hours per week was correlated with the percentage of sputum neutrophils in athletes who trained in cold air [33]. Damage to airway defenses may explain the enhanced risk to respiratory health caused by habitual high-frequency exercise $[12,21]$ Nasal structures, e.g., epithelial cilia, contribute 50$60 \%$ of total respiratory resistance, the first barrier to particle ingress [62]. Muns et al. demonstrated that long-distance runners exhibited decreased nasal mucociliary clearance and ciliary movement [63]. In a study on particle clearance in the respiratory system, the nasal resistance of runners both within and outside a city was significantly reduced after exercise, which increased their susceptibility to $\mathrm{PM}_{2.5}$ exposure [27].

In terms of cardiovascular responses, increased aortic augmentation pressure and aortic pressure index indicate higher pulse-wave velocity and earlier return of the reflected wave, which suggest higher arterial stiffness following $\mathrm{PM}_{2.5}$ exposure $[41,43]$. The positive associations between exposure to $\mathrm{PM}_{2.5}$ and arterial stiffness were weaker in subjects with high exercise frequency, suggesting that long-term habitual exercise is associated with improved cardiovascular fitness and an increase in cardiovascular resistance to air pollutants [12, 15, 16, 64].

Low cardiopulmonary fitness is a key predictor of cardiovascular mortality in healthy subjects and patients with coronary heart disease $[65,66]$. Consistent with our results, in a study of the excess risk of mortality per $10 \mu \mathrm{g} / \mathrm{m}^{3}$ increase in air-pollutant levels in Hong Kong, Wong et al. reported that exercise at a moderate frequency ( $\geq 1$ and $<4 /$ week) had a greater protective effect against cardiopulmonary death attributable to particulate matter and ozone than a low or excessive exercise frequency ( $<1$ or $\geq 4 /$ week) [19]. In a cohort study of air pollution and lung and heart disease, Endes et al. observed that increased brachial-ankle pulse-wave velocity, a biomarker of arterial stiffness, was significantly associated with self-reported $\mathrm{PM}_{2.5}$ and $\mathrm{PM}_{10}$ exposure in physically inactive, but not in physically active, elderly subjects [31]. In addition, as a surrogate biomarker of pre-clinical atherosclerosis, arterial wall thickness decreased following long-term exercise training, which contributed to cardioprotection, but increased after prolonged and repetitive exposure to cardiovascular risk factors, including air pollution [18].

Outdoor physical exercise, including jogging, walking, running, social dancing, and marathon running, remain popular in China despite the severe air pollution [67]. In this study, aortic augmentation pressure following low-level ambient UFP exposure in subjects who preferred outdoor exercise was lower than that in subjects who preferred indoor exercise, but the difference disappeared with high-level UFP exposure. Several studies in areas with low concentrations of ambient $\mathrm{PM}_{2.5}\left(<30 \mu \mathrm{g} / \mathrm{m}^{3}\right)$ reported higher levels of personal and residential indoor than outdoor $\mathrm{PM}_{2.5}$ exposure, possibly due to human activities [68-71]. In highly polluted areas, for instance, in China, the correlation between outdoor and indoor $\mathrm{PM}_{2.5}$ concentrations was stronger at higher ambient pollution levels, suggesting an increased contribution of outdoor pollution to indoor $\mathrm{PM}_{2.5}$ exposure [72, 73]. The difference between the indoor and outdoor $\mathrm{PM}_{2.5}$ concentration decreased with increasing exposure to ambient $\mathrm{PM}_{2.5}$, which may explain why a difference in aortic augmentation pressure between subjects who preferred indoor and outdoor exercise was only observed following exposure to low-level ambient $\mathrm{PM}_{2.5}$.

A panel of subjects completed seven visits under different air-pollution conditions, so all subjects acted as their own controls, which reduced the error associated with intra-individual differences. In addition, repeated measurements of each subject enhanced the power of the LME models [44, 74, 75]. The homogeneous characteristics of the subjects reduced the number and magnitude of fluctuations in the confounders considered in evaluating the combined effects of habitual exercise and $\mathrm{PM}_{2.5}$ exposure in young healthy males $[53,54]$. This study had several limitations. First, the small sample size $(n=20 \times 7)$ limited the statistical power to evaluate the responses associated with exposure to $\mathrm{PM}_{2.5}$. Second, the levels of pollutants were monitored at a fixed monitoring station instead of at a personal level. Although all subjects lived within $2 \mathrm{~km}$ of the monitoring station and had similar time-activity modes, exposure misclassification may have occurred. Because the monitoring station was located near a main road, the error in $\mathrm{BC}$ measurements was considerable. Third, the subjects had relatively high levels of education, similar living habits, and good healthcare, so our findings cannot be generalized to the general population. Fourth, FMPS only measured the number concentration of particles in the size range 
5.6-560 nm, which prevented evaluation of the effects of larger particles. Fifth, due to the similar time-activity modes of the subjects, only exercise frequency and place were recorded in the baseline questionnaire to describe exercise habits. These reflected only some aspects of exercise habits; other important information, such as whether subjects preferred running or swimming, was missed.

\section{Conclusions}

Long-term habitual exercise in severely polluted areas may strengthen the resistance of the cardiovascular system to exposure to $\mathrm{PM}_{2.5}$ but increase the risk of pollutant-related airway inflammation.

\section{Additional file}

Additional file 1 Table S1. Pearson correlation coefficients among air pollutants. Table S2. Pearson correlation coefficients among health outcomes. Table S3. Percent changes ( $\beta$ ) in biomarkers per IQR increases in UFP, with further adjustment for multiple confounders. Table S4. Studies concerning the effects of particles exposure on FeNO, aortic augmentation pressure, and aortic pressure index in healthy young adults. Figure S1-S7. Percent changes in FeNO, IL-2, SBP, DBP, ejection duration, aortic augmentation pressure and aortic pressure index per IQR increases in particles exposure in single pollutant models, respectively. Figure S8. Percent changes in A) aortic pressure index, B) aortic augmentation pressure, C) ejection duration, D) FeNO per IQR increases in particles exposure in two-pollutant models. Figure S9-S11. Percent changes in FeNO with the IQR increases in concentrations of $\mathrm{PM}_{2.5}$ and its constituents stratified by exercise place, BMI, and BFR. Fig. S12-S15. Percent changes in IL-2 with the IQR increases in concentrations of $\mathrm{PM}_{2.5}$ and its constituents stratified by exercise frequency, exercise place, BMI, and BFR. Figure S16-S19. Percent changes in SBP with the IQR increases in concentrations of $\mathrm{PM}_{2.5}$ and its constituents stratified by exercise frequency, exercise place, BMI, and BFR. Figure S20-S23. Percent changes in DBP with the IQR increases in concentrations of $\mathrm{PM}_{2.5}$ and its constituents stratified by exercise frequency, exercise place, BMI, and BFR. Figure S24-S27. Percent changes in ejection duration with the IQR increases in concentrations of $\mathrm{PM}_{2.5}$ and its constituents stratified by exercise frequency, exercise place, BMI, and BFR. Figure S28-S29. percent changes in aortic augmentation pressure with the IQR increases in concentrations of $\mathrm{PM}_{2.5}$ and its constituents stratified by BMI and BFR. Figure S30-S33. percent changes in aortic pressure index with the IQR increases in concentrations of $\mathrm{PM}_{2.5}$ and its constituents stratified by exercise frequency, exercise place, BMI, and BFR. (DOCX $3760 \mathrm{~kb}$ )

\begin{abstract}
Abbreviations
AMP: accumulation mode particles; BC: black carbon; BFR: body fat ratio; BMI: body mass index; Cl: confidence interval; EBC: exhaled breath condensates; FeNO: fractional exhaled nitric oxide; IL-2/1ß/6: interleukin-2/ $1 \beta / 6$; IQR: interquartile range; LMA: linear mixed-effects model; MA: moving average; $\mathrm{PM}_{2.5}$ : particulate matter with an aerodynamic diameter $\leq 2.5 \mu \mathrm{m}$; ppb: parts per billion; PWA: pulse wave analysis; SBP and DBP: peripheral systolic and diastolic blood pressure; SD: standard deviation; UFP: ultrafine particles
\end{abstract}

\section{Acknowledgements}

This work was supported by the Ministry of Science and Technology project [grant number 2015CB553401, YS2017YFGH000700], the Natural Science Foundation of China [grant numbers 41421064, 21190051, 41121004], and Shenzhen Science \& Technology Project [grant number JSGG20170413173425899]. We are greatly thankful to all the subjects in our group.
The English in this document has been checked by at least two professional editors, both native speakers of English. For a certificate, please see: http://www.textcheck.com/certificate/6QvtJX

\section{Funding}

The Ministry of Science and Technology project [grant number 2015CB553401, YS2017YFGH000700]; Natural Science Foundation of China [grant numbers 41421064, 21190051, 41121004]; Shenzhen Science \& Technology Project [grant number JSGG20170413173425899];

\section{Availability of data and materials}

The datasets supporting the conclusions of this article are included within the article and its additional file.

\section{Author's contributions}

XC and WC took part in study design, were responsible for coordinating the study, performed the data analysis, and drafted manuscript. YW took part in study design, health measurement, and manuscript preparation. $\mathrm{YH}$ helped with study design and manuscript preparation. TZ assisted study design and revised the manuscript. All authors read and approved the final manuscript.

\section{Ethics approval and consent to participate}

The study was approved by the Ethics Committee of Peking University Health Sciences Centre (IRB00001052-14076), and written consents were obtained from all subjects.

\section{Consent for publication}

Not applicable.

\section{Competing interests}

The authors declare that they have no competing interests.

\section{Publisher's Note}

Springer Nature remains neutral with regard to jurisdictional claims in published maps and institutional affiliations.

\section{Author details}

${ }^{1}$ State Key Joint Laboratory for Environmental Simulation and Pollution Control, College of Environmental Sciences and Engineering, Peking University, Beijing 100871, China. ${ }^{2}$ The Beijing Innovation Center for Engineering Science and Advanced Technology, Peking University, Beijing 100871, China. ${ }^{3}$ Center of Research and Innovation, Shenzhen Institute of Building Research Co., Ltd., Shenzhen 518049, China.

Received: 16 June 2018 Accepted: 4 December 2018

Published online: 13 December 2018

\section{References}

1. Pope CR, Dockery DW. Health effects of fine particulate air pollution: lines that connect. J Air Waste Manag Assoc. 2006;56:709-42.

2. U.S. EPA (Environmental Protection Agency). Integrated science assessment for particulate matter. 2009. http://cfpub.epa.gov/ncea/cfm/recordisplay. $\mathrm{cfm}$ ?deid=201805\#Download. Accessed 19 Feb 2009.

3. U.S. EPA (Environmental Protection Agency). Report to Congress on black carbon. 2012. https://cfpub.epa.gov/si/si_public_record_report.cfm?Lab= OAQPS\&dirEntryID=240148. Accessed Mar 2012.

4. Brook RD, Rajagopalan S, Pope CR, Brook JR, Bhatnagar A, Diez-Roux AV, et al. Particulate matter air pollution and cardiovascular disease: an update to the scientific statement from the American Heart Association. Circulation. 2010;121(21):2331-78.

5. Brook RD, Rajagopalan S. Particulate matter, air pollution, and blood pressure. Journal of the American Society of Hypertension. 2009;3(5):332-50.

6. Han YQ, Zhu T. Health effects of fine particles (PM_(2.5)) in ambient air. Science China Life Science. 2015;58:624-6.

7. Chen R, Qiao L, Li H, Zhao Y, Zhang Y, Xu W, et al. Fine particulate matter constituents, nitric oxide synthase DNA methylation and exhaled nitric oxide. Environ Sci Technol. 2015:49(19):11859-65.

8. Nichols JL, Owens EO, Dutton SJ, Luben TJ. Systematic review of the effects of black carbon on cardiovascular disease among individuals with preexisting disease. Int J Public Health. 2013;58:707-24. 
9. Rich DQ, Zareba W, Beckett W, Hopke PK, Oakes D, Frampton MW, et al. Are ambient ultrafine, accumulation mode, and fine particles associated with adverse cardiac responses in patients undergoing cardiac rehabilitation? Environ Health Perspect. 2012;120:1162-9.

10. Lin WW, Huang W, Zhu T, Hu M, Brunekreef B, Zhang YH, et al. Acute respiratory inflammation in children and black carbon in ambient air before and during the 2008 Beijing Olympics. Environ Health Perspect. 2011;119:1507-12.

11. Han YQ, Zhu T, Guan TJ, Zhu Y, Liu J, et al. Association between sizesegregated particles in ambient air and acute respiratory inflammation. Science of Total Environment. 2016;565:412-9.

12. Valado A, Tavares PC, Pereira L, Ribeiro CF. Anaerobic exercise and oxidative stress - effect of the intense exercise on nitric oxide and malondialdehyde. In: Bio' 07, proceedings of the 3rd WSEAS international conference on cellular and molecular biology. Biophysics and Bioengineering. 2007;1(1):61-5.

13. Andersen ZJ, de Nazelle A, Mendez MA, Garcia-Aymerich J, Hertel O, Tjonneland A, et al. A study of the combined effects of physical activity and air pollution on mortality in elderly urban residents: the Danish diet, Cancer, and health cohort. Environ Health Perspect. 2015;123:557-63.

14. Gleeson M. Immune function in sport and exercise. J Appl Physiol. 2007;103: 693-9.

15. Kargarfard M, Shariat A, Shaw BS, Shaw I, Lam ET, Kheiri A, et al. Effects of polluted air on cardiovascular and hematological parameters after progressive maximal aerobic exercise. Lung. 2015;193:275-81.

16. Kwon HR, Min KW, Ahn HJ, Seok HG, Lee JH, Park GS, et al. Effects of aerobic exercise vs. resistance training on endothelial function in women with type 2 diabetes mellitus. Diabetes Metab J. 2011;35:364-73.

17. Pedersen BK, Toft AD. Effects of exercise on lymphocytes and cytokines. Brit J Sport Med. 2000;34:246-51.

18. Thijssen D, Cable NT, Green DJ. Impact of exercise training on arterial wall thickness in humans. Clin Sci. 2012;122:311-22.

19. Wong CM, Ou CQ, Thach TQ, Chau YK, Chan KP, Ho SY, et al. Does regular exercise protect against air pollution-associated mortality? Prev Med. 2007 44:386-92.

20. Warburton D, Nicol CW, Bredin S. Health benefits of physical activity: the evidence. Can Med Assoc J. 2006;174:801-9.

21. Lee JY, Lee DC. Cardiac and pulmonary benefits of forest walking versus city walking in elderly women: a randomised, controlled, open-label trial. European Journal of Integrative Medicine. 2014;6:5-11.

22. Zago AS, Kokubun E, Fenty-Stewart N, Park JY, Attipoe S, Hagberg J, et al. Effect of physical activity and T-786C polymorphism in blood pressure and blood flow in the elderly. Arq Bras Cardiol. 2010;95:510-7.

23. Franzoni F, Ghiadoni L, Galetta F, Plantinga Y, Lubrano V, Huang Y, et al. Physical activity, plasma antioxidant capacity, and endothelium-dependent vasodilation in young and older men. Am J Hypertens. 2005;18:510-6.

24. Higashi Y, Yoshizumi M. Exercise and endothelial function: role of endothelium-derived nitric oxide and oxidative stress in healthy subjects and hypertensive patients. Pharmacol Ther. 2004;102:87-96.

25. Karolkiewicz J, Szczesniak L, Deskur-Smielecka E, Nowak A, Stemplewski R, Szeklicki R. Oxidative stress and antioxidant defense system in healthy, elderly men: relationship to physical activity. Aging Male. 2003;6:100-5

26. Nyhan M, McNabola A, Misstear B. Comparison of particulate matter dose and acute heart rate variability response in cyclists, pedestrians, bus and train passengers. Science of Total Environment. 2014;468:821-31.

27. Aydin S, Cingi C, San T, Ulusoy S, Orhan I. The effects of air pollutants on nasal functions of outdoor runners. Eur Arch Oto-Rhino-L. 2014:271:713-7.

28. Daigle CC, Chalupa DC, Gibb FR, Morrow PE, Oberdorster G, Utell MJ, et al. Ultrafine particle deposition in humans during rest and exercise. Inhal Toxicol. 2003;15:539-52.

29. Sharman JE, Cockcroft JR, Coombes JS. Cardiovascular implications of exposure to traffic air pollution during exercise. Qjm-Int J Med. 2004;97:637-43.

30. Goto C, Higashi Y, Kimura M, Noma K, Hara K, Nakagawa K, et al. Effect of different intensities of exercise on endothelium-dependent vasodilation in humans: role of endothelium-dependent nitric oxide and oxidative stress. Circulation. 2003:108:530-5.

31. Endes S, Schaffner E, Caviezel S, Dratva J, Stolz D, et al. Is physical activity a modifier of the association between air pollution and arterial stiffness in older adults: the SAPALDIA cohort study. Int J Hyg Environ Health. 2017; 220(6):1030-8.

32. Giorgini $P$, Rubenfire $M$, Bard $R L$, Jackson EA, Ferri $C$, et al. Air pollution and exercise: a review of the cardiovascular implications for health care professionals. J Cardiopulm Rehabil Prev. 2016;36(2):84-95.
33. Bougault V, Turmel J, St-Laurent J, Bertrand M, Boulet LP. Asthma, airway inflammation and epithelial damage in swimmers and cold-air athletes. Eur Respir J. 2009;33:740-6.

34. Rundell KW. Pulmonary function decay in women ice hockey players: is there a relationship to ice rink air quality? Inhal Toxicol. 2004;16:117-23.

35. Laeremans M, Dons E, Avila-Palencia I, Carrasco-Turigas G, Orjuela JP, et al. Short-term effects of physical activity, air pollution and their interaction on the cardiovascular and respiratory system. Environ Int. 2018;117:82-90.

36. Weichenthal S, Hatzopoulou M, Goldberg MS. Exposure to traffic-related air pollution during physical activity and acute changes in blood pressure, autonomic and micro-vascular function in women: a cross-over study. Part Fibre Toxicol. 2014;11:70

37. Korrick SA, Neas LM, Dockery DW, Gold DR, Allen GA, Hill LB, et al. Effects of ozone and other pollutants on the pulmonary function of adult hikers. Environ Health Perspect. 1998:106(2):93-9.

38. Matt F, Cole-Hunter T, Donaire-Gonzalez D, Kubesch N, Martinez D, et al. Acute respiratory response to traffic-related air pollution during physical activity performance. Environ Int. 2016;97:45-55.

39. Huang W, Wang GF, Lu SE, Kipen H, Wang YD, Hu M, et al. Inflammatory and oxidative stress responses of healthy young adults to changes in air quality during the Beijing Olympics. Am J Respir Crit Care Med. 2012;186:1150-9.

40. Chen $\mathrm{CH}$, Nevo E, Fetics B, Pak PH, Yin FC, Maughan WL, et al. Estimation of central aortic pressure waveform by mathematical transformation of radial tonometry pressure. Validation of generalized transfer function. Circulation. 1997;95:1827-36.

41. Mehta AJ, Zanobetti A, Koutrakis P, Mittleman MA, Sparrow D, Vokonas P, et al. Associations between short-term changes in air pollution and correlates of arterial stiffness: the veterans affairs normative aging study, 2007-2011. Am J Epidemiol. 2014;179:192-9.

42. Nichols WW, Denardo SJ, Johnson BD, Sharaf BL, Bairey MC, Pepine CJ. Increased wave reflection and ejection duration in women with chest pain and nonobstructive coronary artery disease: ancillary study from the Women's ischemia syndrome evaluation. J Hypertens. 2013;31:1447-55.

43. Chirinos JA, Zambrano JP, Chakko S, Veerani A, Schob A, et al. Aortic pressure augmentation predicts adverse cardiovascular events in patients with established coronary artery disease. Hypertension. 2005:45(5):980-5.

44. Shi JJ, Chen RJ, Yang CY, Lin ZJ, Cai J, et al. Association between fine particulate matter chemical constituents and airway inflammation: a panel study among healthy adults in China. Environ Res. 2016;150:264-8.

45. Zhang J, Zhu T, Kipen H, Wang G, Huang W, et al. Cardiorespiratory biomarker responses in healthy young adults to drastic air quality changes surrounding the 2008 Beijing Olympics. Res Rep Health Eff Inst. 2013;174:5-174.

46. Gong J, Zhu T, Kipen H, Wang G, Hu M, et al. Comparisons of ultrafine and fine particles in their associations with biomarkers reflecting physiological pathways. Environ Sci Technol. 2014:48(9):5264-73.

47. Chen X, Sun YT, Zhao Q, Song X, Huang W, et al. Design and characterization of human exposure to generated sulfate and soot particles in a pilot chamber study. J Air Waste Manag Assoc. 2016;66(4):366-76.

48. Barath S, Mills NL, Adelroth E, Olin AC, Blomberg A. Diesel exhaust but not ozone increases fraction of exhaled nitric oxide in a randomized controlled experimental exposure study of healthy human subjects. Environ Health. 2013;12:36.

49. Strak M, Janssen NA, Godri KJ, Gosens I, Mudway IS, et al. Respiratory health effects of airborne particulate matter: the role of particle size, composition, and oxidative potential-the RAPTES project. Environ Health Perspect. 2012; 120(8):1183-9.

50. Lundback M, Mills NL, Lucking A, Barath S, Donaldson K, et al. Experimental exposure to diesel exhaust increases arterial stiffness in man. Part Fibre Toxicol. 2009;6:7

51. Unosson J, Blomberg A, Sandstrom T, Muala A, Boman C, et al. Exposure to wood smoke increases arterial stiffness and decreases heart rate variability in humans. Part Fibre Toxicol. 2013;10:20.

52. Mahmud A, Feely J. Effects of passive smoking on blood pressure and aortic pressure waveform in healthy young adults--influence of gender. Br J Clin Pharmacol. 2004;57(1):37-43.

53. Golan R, Ladva C, Greenwald R, Krall JR, Raysoni AU, et al. Acute pulmonary and inflammatory response in young adults following a scripted car commute. Air Qual Atmos Health. 2018;11(2):123-36.

54. Wauters A, Vicenzi M, De Becker B, Riga JP, Esmaeilzadeh F, et al. At high cardiac output, diesel exhaust exposure increases pulmonary vascular resistance and decreases distensibility of pulmonary resistive vessels. Am J Physiol Heart Circ Physiol. 2015;309(12):H2137-44. 
55. Mirowsky JE, Peltier RE, Lippmann M, Thurston G, Chen LC, et al. Repeated measures of inflammation, blood pressure, and heart rate variability associated with traffic exposures in healthy adults. Environ Health. 2015;14:66.

56. Cui X, Li F, Xiang J, Fang M, Chung MK, et al. Cardiopulmonary effects of overnight indoor air filtration in healthy nonsmoking adults: a double-blind randomized crossover study. Environ Int. 2018;114:27-36.

57. Lucking AJ, Lundback M, Barath SL, Mills NL, Sidhu MK, et al. Particle traps prevent adverse vascular and prothrombotic effects of diesel engine exhaust inhalation in men. Circulation. 2011;123(16):1721-8.

58. Byrd JB, Morishita M, Bard RL, Das R, Wang L, et al. Acute increase in blood pressure during inhalation of coarse particulate matter air pollution from an urban location. J Am Soc Hypertens. 2016;10(2):133-9.

59. Lenters V, Uiterwaal CS, Beelen R, Bots ML, Fischer P, et al. Long-term exposure to air pollution and vascular damage in young adults. Epidemiology. 2010;21(4):512-20.

60. Bard RL, Dvonch JT, Kaciroti N, Lustig SA, Brook RD. Is acute high-dose secondhand smoke exposure always harmful to microvascular function in healthy adults? Prev Cardiol. 2010;13(4):175-9.

61. Cutrufello PT, Smoliga JM, Rundell KW. Small things make a big difference: particulate matter and exercise. Sports Med. 2012;42(12):1041-58.

62. Fonseca MT, Voegels RL, Pinto KM. Evaluation of nasal volume by acoustic rhinometry before and after physical exercise. Am J Rhinol. 2006;20:269-73.

63. Muns $G$, Singer P, Wolf F, Rubinstein I. Impaired nasal mucociliary clearance in long-distance runners. Int J Sports Med. 1995;16:209-13.

64. Ciolac EG. High-intensity interval training and hypertension: maximizing the benefits of exercise? Am J Cardiovasc Dis. 2012;2(2):102-10.

65. Myers J, Prakash M, Froelicher V, Do D, Partington S, Atwood JE. Exercise capacity and mortality among men referred for exercise testing. N Engl J Med. 2002;346:793-801.

66. Keteyian SJ, Brawner CA, Savage PD, Ehrman JK, Schairer J, Divine G, et al. Peak aerobic capacity predicts prognosis in patients with coronary heart disease. Am Heart J. 2008;156:292-300.

67. Hu L, Zhu L, Xu YP, Lyu JY, Imm K, et al. Relationship between air quality and outdoor exercise behavior in China: a novel mobile-based study. Int J Behav Med. 2017:24(4):520-7.

68. Branis M, Safranek J, Hytychova A. Exposure of children to airborne particulate matter of different size fractions during indoor physical education at school. Build Environ. 2009;44(6):1246-52.

69. Nasir ZA, Colbeck I. Particulate pollution in different housing types in a UK suburban location. Sci Total Environ. 2013;445:165-76.

70. Lai HK, Kendall M, Ferrier H, Lindup I, Alm S, et al. Personal exposures and microenvironment concentrations of PM2.5, VOC, NO2 and CO in Oxford, UK. Atmos Environ. 2004;38(37):6399-410.

71. O'Connell S, Au-Yeung HK, Gregory CJ, Matthews IP. Outdoor and indoor respirable air particulate concentrations in differing urban traffic microenvironments. J Toxicol Environ Health A. 2008:71(16):1069-72.

72. Lin Y, Zou J, Yang W, Li C. A Review of Recent Advances in Research on PM2.5 in China. Int J Env Res Pub He. 2018; 15(3): 438.

73. Yuan Y, Luo Z, Liu J, Wang Y, Lin Y. Health and economic benefits of building ventilation interventions for reducing indoor PM2.5 exposure from both indoor and outdoor origins in urban Beijing, China. Sci Total Environ. 2018;626:546-54.

74. Cavallari JM, Eisen EA, Fang SC, Schwartz J, Hauser R, et al. PM2.5 metal exposures and nocturnal heart rate variability: a panel study of boilermaker construction workers. Environ Health. 2008;7:36.

75. Wei Y, Han IK, Shao M, Hu M, Zhang OJ, et al. PM2.5 constituents and oxidative DNA damage in humans. Environ Sci Technol. 2009:43(13):4757-62.

Ready to submit your research? Choose BMC and benefit from:

- fast, convenient online submission

- thorough peer review by experienced researchers in your field

- rapid publication on acceptance

- support for research data, including large and complex data types

- gold Open Access which fosters wider collaboration and increased citations

- maximum visibility for your research: over $100 \mathrm{M}$ website views per year

At BMC, research is always in progress.

Learn more biomedcentral.com/submissions 